\title{
Blockchain-based Life Cycle Assessment: An Implementation Framework and System Architecture
}

Citation: Abraham Zhang, Ray Y Zhong, Muhammad Farooque, Kai Kang, V G Venkatesh. (2020)

Blockchain-based life cycle assessment: An implementation framework and system architecture, Resources, Conservation and Recycling, 152. https://doi.org/10.1016/j.resconrec.2019.104512. Share Link (valid before November 22, 2019): https://authors.elsevier.com/a/1Zqkk3HVLKeNVv

Abraham Zhang (corresponding author, E-mail: abraham.zhang@aut.ac.nz) ${ }^{\text {a, b }}$, Ray Y Zhong $^{\mathrm{c}}$, Muhammad Farooque ${ }^{\mathrm{a}, \mathrm{d}}$, Kai Kang ${ }^{\mathrm{c}}$, V G Venkatesh ${ }^{\mathrm{e}}$

a Auckland University of Technology (AUT) Business School, AUT University, Private Bag 92006, Auckland 1142, New Zealand

${ }^{\mathrm{b}}$ Lumen Research Institute, Excelsia College and Indiana Wesleyan University, 69-71 Waterloo Road, Macquarie Park, NSW 2113 Australia

${ }^{c}$ Department of Industrial and Manufacturing Systems Engineering, The University of Hong Kong, Hong Kong

${ }^{\mathrm{d}}$ Sukkur IBA University, Sukkur, Pakistan

e Ecole de Management de Normandie, 30 Rue de Richelieu, 76087 Le Havre, France 


\begin{abstract}
Life cycle assessment (LCA) is widely used for assessing the environmental impacts of a product or service. Collecting reliable data is a major challenge in LCA due to the complexities involved in the tracking and quantifying inputs and outputs at multiple supply chain stages. Blockchain technology offers an ideal solution to overcome the challenge in sustainable supply chain management. Its use in combination with internet-of-things (IoT) and big data analytics and visualization can help organizations achieve operational excellence in conducting LCA for improving supply chain sustainability. This research develops a framework to guide the implementation of Blockchain-based LCA. It proposes a system architecture that integrates the use of Blockchain, IoT, and big data analytics and visualization. The proposed implementation framework and system architecture were validated by practitioners who are experienced with Blockchain applications. The research also analyzes system implementation costs and discusses potential issues and solutions, as well as managerial and policy implications.
\end{abstract}

Keywords: Blockchain; Life cycle assessment; Supply chain sustainability; Environmental sustainability; Operational excellence

Article Classification: Research Article 


\section{Introduction}

In the last few decades, environmental issues including depletion of natural resources, global warming, chemical pollution and loss of biodiversity have been of great concern to the society at large (Luthra and Mangla, 2018). Businesses are increasingly being held responsible for their actions affecting environmental sustainability. In this regard, the management of environmental issues requires reliable tools for measuring and quantifying the environmental impacts of business activities (Balaguera et al., 2018).

Life cycle assessment (LCA) has been widely used for the assessment of environmental impacts associated with all the stages of a product system (i.e., from raw material acquisition or generation, through production, distribution, use and final disposal) (Corcelli et al., 2019; Krishna et al., 2017; UNEP, 2012). The main users of LCA include the governments, nongovernmental organizations (NGOs), and a wide variety of industrial sectors. LCA has been used by industries for identifying opportunities to reduce the environmental impacts of their operations and supply chain activities (Lake et al., 2015). It helps design more sustainable products, and provide data for realistic marketing claims which inform consumers' choices through environmental labeling and declarations (Levasseur et al., 2016). It also serves as a reference methodology for decision support in environmental policies and programs, for example, in the European Environmental Footprint (EC, 2013) and in the European Union Better Regulation Toolbox (EC, 2015).

Despite its popularity, LCA faces a key challenge in collecting reliable data efficiently across the supply chain. From a theoretical viewpoint, the LCA results are only as reliable as the quality of the input data. However, in practice, obtaining reliable data could be very challenging, especially when dealing with new products (Hospido et al., 2010). Theoretically, LCA should account for all inputs of a product system. Yet, most LCA studies fail to do so because practically it is quite difficult to collect data across the supply chain which often involves many businesses that are geographically dispersed (Genovese et al., 2017; Zhang et al., 2013). The academia has significantly contributed to the LCA theory and methodological developments, however, there is still a general discrepancy between the theory and practice of LCA (Baitz et al., 2013; Hollberg and Ruth, 2016). The academia needs to understand the practical boundaries of the application side whereas, the industry needs to learn the new scientific methods and innovations coming from academia (Baitz et al., 2013). There is a dire need to strive for operational excellence (Jakhar et al., 2018; Zhang et al., 2016) in conducting LCAs; aiming towards improving the environmental sustainability performance of supply chains (Mangla et al., 2019).

Blockchain technology offers an ideal solution to overcome the above-mentioned challenges to achieve operational excellence in conducting LCA. Blockchain technology first appeared in the cryptocurrency field (i.e., bitcoin) as a technology to support transactions (Nakamoto, 
2008). However, new applications of Blockchains in financial services, insurance, food, health care, supply chain management and government (Queiroz et al., 2019; Wang et al., 2019) provide clear evidence of its potential to disrupt many traditional industries (Scott et al., 2017; White, 2017). Blockchain technology works in a distributed data structure based on a peer-topeer network (Christidis and Devetsikiotis, 2016; Marsal-Llacuna, 2018) where blocks are linked by cryptographic hashes (Conte de Leon et al., 2017) with copies in all their nodes (AlSaqaf and Seidler, 2017; Scott et al., 2017). Other distinctive features include data security, tamper-proof transactions, and data validation among the network members within a distributed ledger (Queiroz et al., 2019). These features make the transactions records virtually immutable (Adams et al., 2017; Cai and Zhu, 2016; Grewal et al., 2018).

Prior research suggests that Blockchain technology adoption can greatly facilitate green and sustainable practices in supply chains (Kouhizadeh and Sarkis, 2018; Saberi et al., 2019). When combined with other technologies such as big data analytics and internet-of-things (IoT) (Aryal et al., 2018b), Blockchain technology "could be used to create a permanent, shareable, actionable record of every moment of a product's trip through its supply chain" thus providing seamless product traceability, authenticity and legitimacy (Wang et al., 2019, p. 62). For example, application of Blockchain technology and smart devices has significantly improved the compliance measure of Emission Trading Scheme (ETS) as opposed to conventional ETS policy (Fu et al., 2018; Khaqqi et al., 2018). Apparently, Blockchain offers great potential in overcoming the challenges associated with traditional LCA methodologies, as mentioned earlier. The need to integrate LCA and Blockchain from both a theoretical and practical backgrounds offers great value. To the best of our knowledge, there is no prior research done in this area, mainly due to the disruptive nature of the technology. Moreover, the extant literature is lacking a guiding framework integrating Blockchain and other relevant technologies for conducting an LCA. Therefore, this research is set to achieve the following objectives:

1. To develop an implementation framework for guiding the integration of Blockchain and other relevant technologies in conducting LCA for achieving operational excellence

2. To present a system architecture of Blockchain-based LCA system for managing the environmental performance of supply chains

To achieve these objectives, this research addresses the following specific research questions:

1. How to integrate Blockchain and other smart enabling technologies into multiple LCA stages to make the processes more efficient and effective?

2. What is the working mechanism of Blockchain-based LCA and what applications should be included in for managing the environmental performance of supply chains? 
Both the implementation framework and the system architecture developed in this research are validated by experienced practitioners. The proposed Blockchain-based LCA system can drastically improve the efficiency and effectiveness in conducting LCA when compared to the traditional approaches.

The remainder of the paper is organized as follows. Section 2 reviews the relevant literature on Blockchain technology and LCA. Section 3 presents an implementation framework of Blockchain-based LCA. Section 4 develops a system architecture that integrates the use of Blockchain, IoT, and big data analytics and visualization for LCA. It also analyzes the cost of developing such a system. Section 5 discusses potential issues and solutions, as well as managerial and policy implications. Section 6 concludes the research.

\section{Literature Review}

\subsection{Blockchain Technology}

Blockchain is a distributed ledger that can record transactions between any two parties efficiently in a verifiable and permanent way on a global basis (Iansiti and Lakhani, 2017; Li et al., 2019). The Blockchain concept was proposed, along with Bitcoin by Satoshi Nakamoto in 2008 (Nakamoto, 2008). The technology facilitates a decentralized consensus by maintaining a digital record of events using multiple blocks, which are embedded in programs. Each block is identified by its cryptographic hash and it is connected with others based on the hash of the previous block to form a chain of blocks (Bahga and Madisetti, 2016). The individual block stores the negotiated terms and verifies the outcome. The technology adopts a system of permanent stamp driving a collective responsibility among stakeholders for data safety and reliability (Puthal et al., 2018). The system authenticates every transaction by the agreement of more than half of the members participating in the network (Tama et al., 2017). The working mechanism leads to a lower risk of downtime, censorship, and data falsification (Beck et al., 2017; Li et al., 2018a; Nakamoto, 2008). Researchers expect Blockchain to facilitate a high degree of digital transformation with a level of objectivity where no one is in full control or having absolute power and with a broad range of applications in multiple domains (Beck et al., 2017).

In recent times, different types of Blockchains are constructed and they include public, consortium, and private Blockchains, which can be adopted in different scenarios ( $\mathrm{Li}$ et al., 2018a; Li et al., 2018b). Compared with existing information systems, there are four key characteristics in the Blockchain, including decentralization, security, auditability, and smart execution (Saberi et al., 2019). Due to its advantages, the general pattern of interest in the Blockchain has shown exponential growth starting at the end of 2015 due to its reliability (Treiblmaier, 2018). It directly or indirectly enhances information transparency across the supply chain and reduces the chances of data manipulations, by minimizing the role of 
intermediaries whose services are often vulnerable to crash, frauds, and hacks (Tapscott and Tapscott, 2017). Subsequently, the technology has been widely presented and studied in currency and finance domains, and further applications should look beyond economics and markets; particularly in the fields of government, health, and literature (Swan, 2015). Yuan and Wang (2018) investigated Blockchain and cryptocurrencies systematically. They designed a six-layer reference model of the Blockchain framework and also addressed potential applications of Blockchain and cryptocurrencies.

Yue et al. (2016) proposed a Healthcare Data Gateway architecture based on Blockchain to enable patients to own, control, and share their data easily and securely without violating privacy. Li et al. (2018b) suggested a cross-enterprise framework based on Blockchain to achieve a higher level of sharing of knowledge and services in manufacturing ecosystems, allowing the company to develop scalable and flexible business at a lower cost and improve the overall quality, efficiency and effectiveness of manufacturing services in a secure and controlled manner. Viriyasitavat et al. (2018) proposed a Blockchain-based business process management framework for achieving operational excellence in the evaluation and transferring of quality of services in the workflow composition and management. Sikorski et al. (2017) employed Blockchain technology to facilitate machine-to-machine (M2M) interactions in a M2M electricity market in the context of the chemical industry. Tama et al. (2017) deliberated its application in the digital content distribution system, IoT security system, and the advanced authorization management system. Apparently, Blockchain technology has a significant role in rating and trust evaluation schemes.

Recently, potential Blockchain applications were explored for improving supply chain sustainability. For instance, an agri-food supply chain traceability system was developed to guarantee food safety based on radio frequency identification (RFID) and Blockchain (Tian, 2016). Francisco and Swanson (2018) showed that Blockchain could bring supply chain transparency to a new level and expose negative practices such as child labor in the upstream manufacturing process and the unethical use of rainforest resources. In addition, Saberi et al. (2019) classified the barriers of Blockchain technology adoption into four categories, interorganizational, intra-organizational, technical and external barriers, and presented directions to overcome these barriers. Kouhizadeh and Sarkis (2018) investigated activities across and within the supply chain and provided some insights into the diversified sustainability-oriented opportunities associated with Blockchain technology. Overall, the technology enhances the autonomy of the information system since it functions more independently with no or fewer intermediaries and thereby computation power of this distribution system is enriched through the participation of peer members (Viriyasitavat et al., 2018). Franz and Kirchmer (2012) deliberated on value-driven process management by integrating the Blockchain technology for improving the workflow. This is achieved through the integration of cross-organizational 
business processes and by eliminating manual operations, ascertaining and extending the role of Blockchain technology in product LCA.

\subsection{Life Cycle Assessment}

Increasingly, Life cycle thinking is gaining prominence in practice for addressing sustainability-related challenges in production and consumption. LCA is a relevant and popular tool for evaluating environmental impacts relating to the entire production value chain of a product throughout its lifecycle or lifetime (Roy et al., 2009). The technique considers multicriteria attributes with a cradle-to-grave perspective (from raw material to disposal), which is complex for analysis. Moreover, it works as an interdisciplinary framework, wherein the outcomes are influential for making decisions around marketing, product design and selection, and strategic planning (Weidema et al., 2004). Technically, it encompasses not only the assessment of products, but also processes that include raw material processing, manufacturing, transportation, distribution, return and reuse, recycling, and final disposal (Chau et al., 2015; Gbededo et al., 2018). Major economies including the USA, Japan, Korea, Canada, Australia, China, and India have started to treat LCA as a core element of environmental policy formulation (Guinée et al., 2011). In the USA and the European Union, LCA is a mainstream tool for providing key inputs to product declarations and green public procurement policy framework (Notarnicola et al., 2017). In addition, it provides a basis for managing eco-labeling requests of consumers, businesses, and NGOs (Jensen, 1998).

Many industries employ LCA (Roy et al., 2009), for example, construction (Chau et al., 2015), solid waste management (Erses Yay, 2015), agriculture (Cerutti et al., 2014; Notarnicola et al., 2017), food manufacturing (Egilmez et al., 2014), renewable energy (Asdrubali et al., 2015), biology (Pérez-López et al., 2014), and transportation (Bauer et al., 2015). Due to its widespread application and importance, LCA has earned a space in the ISO standards (Guinée and Heijungs, 2017). ISO 14040 to 14043 standards define the principles, framework requirements, and guidelines for undertaking LCA (Rebitzer et al., 2004). Moreover, in the last decade, European Commission's Integrated Product Policy (IPP) has led to the development of a practical guide to LCA, which is complementary to the ISO standards (EC, 2012). On similar lines, a life cycle initiative was launched by the United Nations Environment Program (UNEP) (Jolliet et al., 2005).

The standard LCA system has four main stages such as goal and scope definition, inventory analysis, impact assessment, and interpretation alongside each of these three stages (Muralikrishna and Manickam, 2017). It primarily requires quantitative data to analyze the raw material input, energy consumptions, product output, and environmental releases of the system. The first stage, goal and scope definition, outlines the purpose, mission, functional units, and boundaries of the system. The second stage, inventory analysis, describes input data required for analysis, and how to collect and validate them. It involves a technical modeling system that 
covers the materials used in all product stages ranging from manufacturing to disposal. In the third stage, environmental impacts and resources used are assessed, based on the data from inventory analysis (Buyle et al., 2013). The interpretation stage is alongside each of these three stages. It involves the critical review, determination of data sensitivity, and communication of results (Rebitzer et al., 2004). The above phases primarily require two types of data, foreground and background data. While the former one comprises product-level information, the later one covers the details of energy, transport, and waste management systems. The reliability of LCA results is dependent on the quality of the input data (von Bahr and Steen, 2004). Different sample selection may lead to different results due to weak links in popularizing the data (Cooper et al., 2013; Song et al., 2018). In fact, collecting reliable data is perceived as a significant challenge in LCA based works, especially when dealing with new products (Hospido et al., 2010).

Traditional LCA methodologies work within system boundaries, which are defined by the researchers to account for an impact assessment (Genovese et al., 2017). However, according to Nasir et al. (2017), the subjective judgment of LCA boundaries may lead to variable and uncertain results (Christensen et al., 2007; Matos and Hall, 2007). For complex systems such as supply chains, LCA studies often fail to account for all possible inputs of a product system (Genovese et al., 2017). In addition, there is always some degree of uncertainty associated with the input data for LCA studies (Ciroth et al., 2004). In such cases, laboratory experiments and computer modeling may be used (Norgate et al., 2007; von Gleich et al., 2008), but severe inconsistencies, weak universality of research methods and inaccuracies have been found when scaling to industrial applications (Hospido et al., 2010). Furthermore, LCA methodologies are posed with a challenge to account for benefits (including data processing) from recycling materials and quantifying the effect of substitution and downgrading factors in a circular economy (Niero et al., 2016). In a circular supply chain (Farooque and Zhang, 2017; Farooque et al., 2019b; Mangla et al., 2018), materials are regenerated or used in continuous, multiple and/or circular loops (Farooque et al., 2019a; Niero and Olsen, 2016; Schroeder et al., 2018).

To overcome these practical challenges, the international LCA community is on a constant endeavor to standardize data types used in the analysis, by focusing on systematizing the data collection process and data quality (Roy et al., 2009). However, this standardization exercise faces its own problems related with data synchronization, the rapid development of technologies, and location-specific issues, which have often not been focused on adequately (Guinée et al., 2009; Notarnicola et al., 2017). On the flip side, this development has influenced the rapid expansion of information and knowledge sharing network under the broad LCA framework (Roy et al., 2009). Consequently, it directs LCA analysis to move towards big data by combining with other proven methods including Data Envelopment Analysis, which eventually enhance the transparency and reliability of impact analyses (Song et al., 2018). Such 
developments encourage researchers to adopt other sophisticated technologies including the Blockchain technology in LCA.

In summary, the review recognizes LCA as an important and widely used tool for managing sustainability performance. However, its application faces major challenges in collecting reliable data. So far, little research has explored the use of disruptive Blockchain technology for LCA. The researchers believe that Blockchain can drastically improve the effectiveness and efficiency of collecting, analyzing, and disseminating data related to environmental impacts for conducting LCA. This research narrows the knowledge gap by developing an implementation framework and system architecture of the Blockchain-based LCA system.

\section{Implementation Framework}

The researchers propose a Blockchain-based LCA framework in Figure 1 for integrating Blockchain and other smart enabling technologies into multiple LCA stages to make the processes more efficient and effective. As mentioned earlier, LCA consists of four stages: goal and scope definition, inventory analysis, impact assessment, and interpretation (Muralikrishna and Manickam, 2017). Blockchain-based LCA uses smart enabling technologies to achieve operational excellence at all four stages. The following paragraphs explain the working mechanisms of the smart enabling technologies in conducting LCA and the direct applications of Blockchain-based LCA.

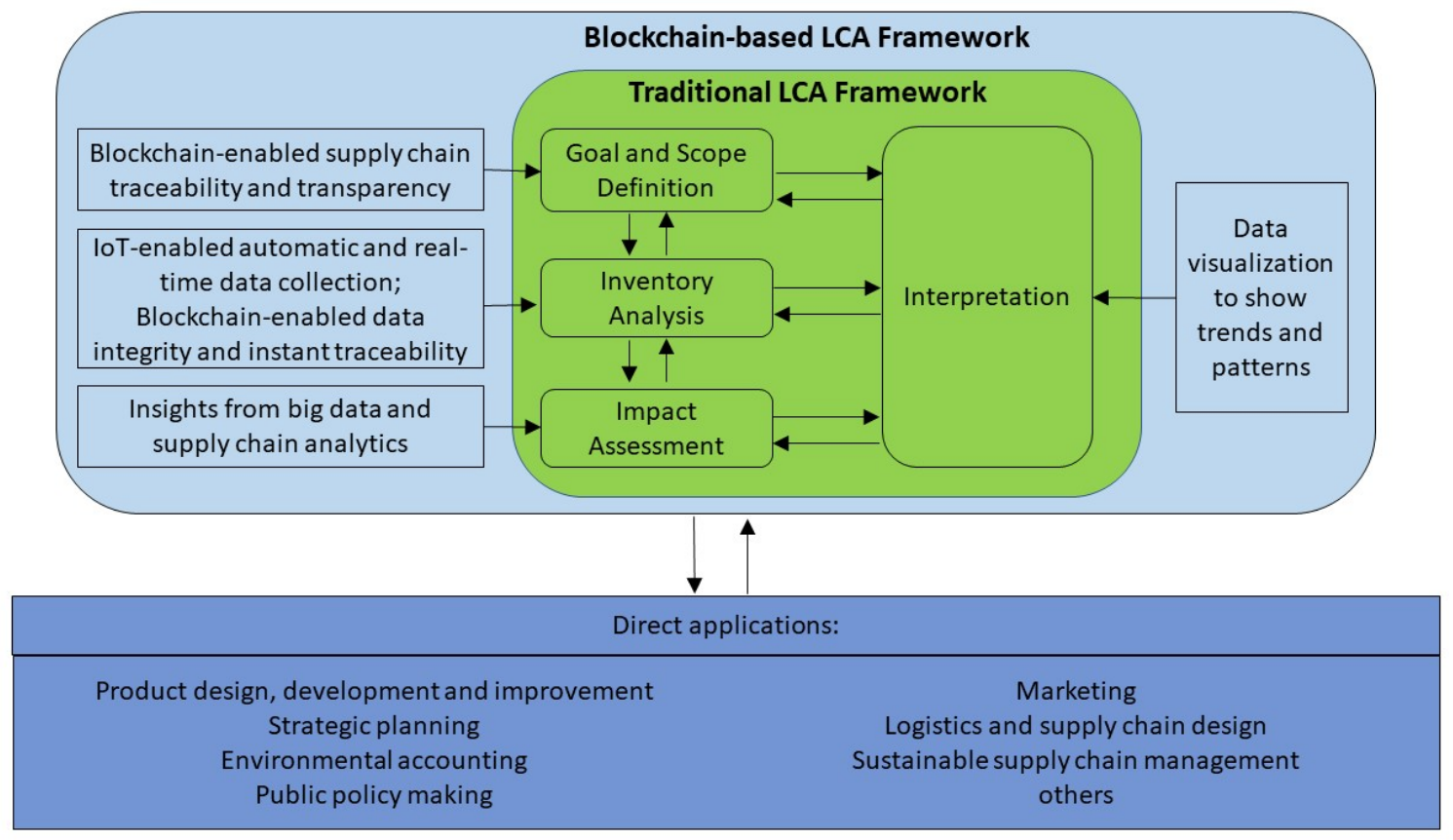

Source: Authors; (Muralikrishna and Manickam, 2017)

Figure 1. Blockchain-based LCA Framework 
The first stage of LCA defines the goal and scope. A comprehensive LCA should include all supply chain stages of a product or process life cycle: raw material acquisition, manufacturing, use/reuse/maintenance, and recycle/waste management. However, constraints such as availability of data, the time required to conduct the LCA, and the financial resources eventually determine which stages can be included in the scope of the LCA. Blockchainenabled supply chain traceability and transparency can remove the constraints associated with data acquisition for LCA. It also minimizes the need for subjective judgment of the functional unit as practiced in traditional LCAs (Christensen et al., 2007; Matos and Hall, 2007). For Blockchain-based LCA, the additional step required at this stage is to determine the extent of technology integration corresponding to the information needs of the LCA study. If a Blockchain-based information system is already in place for a supply chain, it will be a relatively easy task to define the goal and scope of a LCA study because of the traceability and transparency provided by the Blockchain technology.

The second stage of LCA, inventory analysis, quantifies the material and energy flows of the product system including other exchanges within the natural environment (e.g., waste flows and emissions) related to the functional unit (Rebitzer et al., 2004). Blockchain and other enabling technologies can overcome the limitation of the traditional LCA methodologies not being able to account for all possible inputs of complex product supply chains (Genovese et al., 2017). They also make it possible to quantify the material regeneration and restoration effects within a circular supply chain (Farooque and Zhang, 2017; Farooque et al., 2019b; Mangla et al., 2018; Niero et al., 2016; Niero and Olsen, 2016). In this regard, Blockchainbased LCA relies on IoT technologies which provide seamless capabilities for capturing realtime lifecycle data automatically. This data is then recorded using Blockchain technology, which ensures that the data integrity is maintained. More importantly, Blockchain technology enables instant traceability of data, which is not possible in a traditional system. A traditional system may have data available at multiple stages of the supply chain, but the data is not shared. It could be a very time-consuming task to obtain relevant data from multiple supply chain actors across the globe. For example, a Blockchain-based food traceability system tried by Walmart was able to reduce the time needed to trace the provenance of mangoes in the US from 7 days to 2.2 seconds (Hyperledger, 2018).

In the third phase of LCA, impact assessment evaluates the product life cycle (traditionally performed on a functional unit basis), which provides an indicator of the potential impacts in several impact categories (e.g., water use, climate change, etc.) (Krishna et al., 2017; Rebitzer et al., 2004). With more reliable data inputs, Blockchain-based LCA provides more accurate assessments. IoT technologies powered by sensors and devices can generate very large-scale real-time data (e.g., big data). Big data and supply chain analytics can be used to discover insights which will contribute to better and faster decision making based on data that was previously inaccessible or unusable. 
Lastly, life cycle interpretation occurs at every stage in an LCA (Rebitzer et al., 2004). The ISO 14043 standard recommends three steps for conducting life cycle interpretation. These steps include 1) identification of the significant issues based on the inventory analysis and impact assessment, 2) evaluation which considers completeness, sensitivity, and consistency checks, 3) conclusions, recommendations, and reporting (Scientific Applications International Corporation, 2006). Blockchain-based LCA ensures that all data elements which contribute significantly to the outcome of the results are properly assessed and only the validated results are used to draw conclusions from the LCA study. Furthermore, Blockchain-based LCA is also powered by data visualization tools to produce graphical insights of the LCA data. This enables data analyses from different perspectives to identify patterns, connections, and relationships, as well as to understand and interpret large amounts of data very quickly.

Blockchain-based LCA can have many direct applications for improving environmental sustainability. These applications include product design, development and improvement, strategic planning, environmental accounting, public policymaking, marketing, logistics and supply chain design, sustainable supply chain management, amongst others (Muralikrishna and Manickam, 2017). For example, product designers need to incorporate environmental criteria into their design decisions. They can obtain data from a Blockchain-based LCA system used for similar products to aid their processes of designing new products. Environmental accounting, which has become increasingly popular, will be made much easier with a Blockchain-based LCA system. Logistics and supply chain design have a large impact on carbon emissions generated from freight movements. Blockchain-based LCA can inform better logistics and supply chain design decisions for improving supply chain sustainability performance.

The implementation framework presented in Figure 1 was validated by three experienced practitioners who have expertise in Blockchain technology. The lead researcher sent to the practitioners via email a copy of the implementation framework including its descriptions and requested their feedback for validating and improving the framework. These practitioners play different roles in Blockchain technology adoption. Among them, one practitioner is a Blockchain technology provider who has won multiple contracts to develop Blockchain-based systems for businesses. The other two practitioners include a Blockchain technology user from the forestry sector and a senior management consultant with over 20 years of experiences in advising clients in the use of improvement methodologies and technologies, including Blockchain. They all approved the general validity of the implementation framework. They also provided some constructive feedback according to the request of the lead researcher. After a telephone conversation with the Blockchain technology provider, the lead researcher made some revisions to improve the initial draft of the implementation framework. A similar procedure was followed for developing the system architecture presented in the next section. 


\section{System Architecture}

In this section, an overall description of the system architecture is provided in section 4.1 to explain how the Blockchain-based LCA framework is converted into a Blockchain-based LCA system, what other technologies are used and why they are adopted. Then, the system is described in detail about its multiple layers in sections 4.2 and 4.3. Finally, the cost of the system is estimated in section 4.4.

\subsection{Overall Description}

According to the Blockchain-based LCA framework presented in section 3, the researchers propose a system architecture of Blockchain-based LCA system in Figure 2. The system has four layers: infrastructure layer, Blockchain services layer, applications layer, and users layer. The infrastructure layer serves as the foundation of the proposed system architecture to collect, transmit, and record data. The Blockchain services layer serves as a bridge connecting the infrastructure layer and the applications layer through cleansing, processing and analyzing data. The applications layer is responsible for visualizing data and assisting in decision making. The users utilize the system through the users' layer. Specifically, these four layers provide functions corresponding to the needs at the four LCA stages. The first stage, goal and scope definition, is initiated by users with various aims and objectives in the users' layer. In order to fulfill the goal, all related data have to be collected accurately and transmitted and recorded reliably for the inventory analysis stage, which is the role of the infrastructure layer. Given the data stored in Blockchain network, big data analytics are required to process data so as to provide accurate impact assessments, which are enabled by the Blockchain services layer. Finally, results of impact assessments can be accessed by users through some standardized applications.

The system architecture is mainly enabled by two other technologies besides the Blockchain technology: IoT technologies and big data analytics, both of which are widely applied in various fields. With the adoption of IoT technologies, data can be collected automatically without human involvement, when physical objects are equipped with electronics, software, sensors, actuators and connectivity functionalities (Atzori et al., 2010). Recently, IoT technologies have been utilized to perceive and access manufacturing resources (Tao et al., 2014b), to develop a configurable information service platform for product lifecycle assessment (Cai et al., 2014) and to monitor the user's health and activate remote assistance (Amendola et al., 2014). In addition, given data collected automatically by IoT technologies, big data analytics has been utilized to extract valuable insights, such as logistics trajectory (Zhong et al., 2015), standard operation time (Zhong et al., 2014), and enterprises' competitive advantages (Galletti and Papadimitriou, 2013). 
Typically, IoT technologies and big data analytics are applied within a company where data can be transferred reliably. For conducting LCA, however, data may need to be transferred across the supply chain, some of whose members might have a strong motivation to benefit from sharing untruthful data with other supply chain members. Moreover, it is often a challenge to share data in a flexible manner. Blockchain technology can overcome the challenge by sharing the captured data reliably before they are analyzed and serves as a bridge to connect IoT technologies with big data analytics seamlessly.

\subsection{Infrastructure and Blockchain Services}

From the bottom-up, the infrastructure layer consists of the hardware layer and software layer. The hardware layer provides smart sensors to enable the deployment of IoT technologies. Local servers and storage to store data that is collected by smart sensors or obtained from the Blockchain. The network transmits real-time data collected by smart sensors in an easy-todeploy and flexible-to-configure way. Smart sensors are used to enhance traditional physical machinery's abilities to monitor and trace the life cycle impact of a product. Typical smart sensors related to LCA include smart electricity meters, smart water meters, RFID readers, intelligent heat meters, intelligent gas meters, and fiber optical sensors (Tao et al., 2014a). A variety of smart sensors can be deployed at the multiple phases of a product's entire lifecycle. For example, in the production phase, once machine operators receive components to be processed, they tap their staff cards on a reader deployed on the machines to activate the process. The machines start processing the components and smart electricity meters record electricity consumption. Data are transmitted to the software layer automatically. At the software layer, a gateway operating (GOS) system is a middleware system, which serves as a bridge that connects physical machinery with upper layers. GOS mainly controls data transmissions and transmission mechanisms which control what types of data can be transmitted in the appropriate time periods. Therefore, the environmental impacts of a product can be monitored and evaluated at all life cycle stages from sourcing, production, distribution, usage to reuse/regeneration (Chau et al., 2015). Note that materials reuse/regeneration is part of the circular supply chain management, which was defined by Farooque et al. (2019b). Therefore, this system architecture goes beyond the "cradle-to-grave" approach embedded in the traditional LCA framework, to support a "cradle-to-cradle" approach that is required for a transition to a circular economy. 


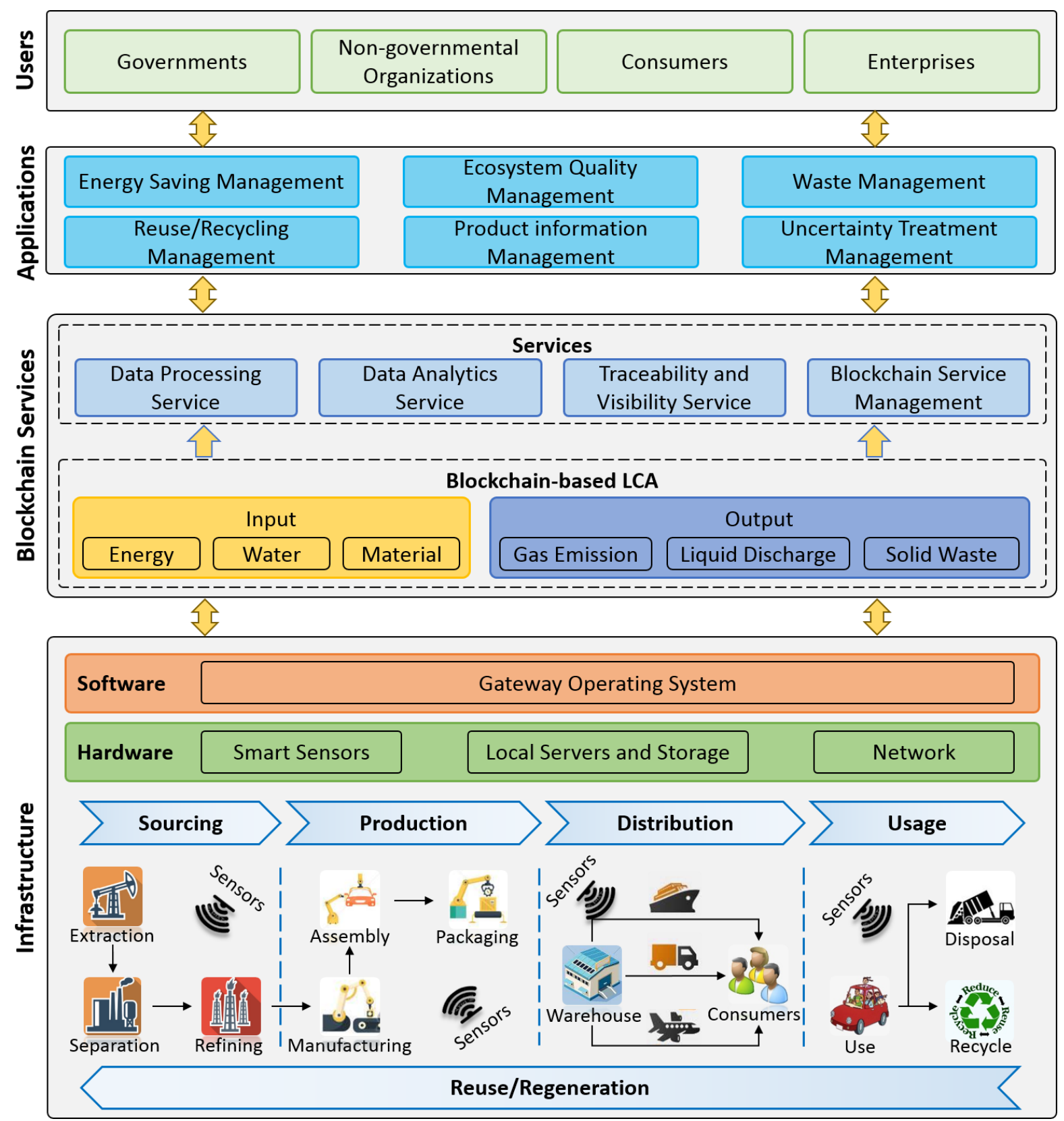

Figure 2. Blockchain-based Life Cycle Assessment System

The Blockchain services layer is responsible for recording and processing the LCA-related data. There are two types of data: input resource consumption data and output waste emission data. From sourcing to reuse/regeneration phase, these data will be recorded in blocks that are used to create diverse Blockchains such as energy Blockchains and gas emission Blockchains. For example, when lathe operators process components, electricity consumption, and solid waste data are generated and captured by smart sensors, and the data are transmitted to Blockchain network through GOS. Such data form electricity consumption and solid waste blocks are connected with their Blockchains respectively. Based on these Blockchains, the Blockchain-based LCA system offers users four key services to achieve the integration of data and to provide value-added activities, which help users to analyze the environmental impacts 
of a product. These services are data processing service, data analytics service, traceability and visibility service, and Blockchain service management. Data processing service is responsible for cleansing, classifying, sorting, and calculating data. For example, carbon footprints are calculated in this service when all the input resource consumption data is available. Data analytics service is used to produce meaningful information from processed data, which plays an important role in making decisions. Various technologies including machine learning, statistical methods, and data mining, are applied to simulate human minds in order to discover meaningful patterns ( $\mathrm{Li}$ et al., 2018b). Traceability and visibility service provides users with data visualization tools. The processed and analyzed data can be encoded and presented by statistical graphics and information graphics, which help users understand the environmental impacts of a product life cycle intuitively. Some statistical reports are also generated from this service. Blockchain service management is responsible for managing the Blockchains and upgrading services in the Blockchain service layer.

\subsection{Applications and Users}

The applications layer provides six key applications. The first four applications deal with specific environmental aspects: energy-saving management, ecosystem quality management, waste management, and reuse/recycling management. The other two applications, product information management, and uncertainty treatment management serve some generic purposes.

The goal of energy-saving management is to reduce the amount of energy consumed in the product life cycle. Energy-saving has attracted much attention owing to severe environmental issues (Tao et al., 2014a). With the application of Blockchain and IoT technologies, data on energy consumption of a product's entire life cycle can be collected and traced. Thus, the energy consumption level can be evaluated and analyzed, and then energy conversion and recycling can be calculated overall life cycle stages (Zuo et al., 2018). Based on the evaluation and analysis, product designers can modify design schemes and select suitable materials and components to achieve low energy consumption. Engineers can improve the production process and choose better scheduling to save energy. Consumers can be informed to use the product properly to reduce unnecessary energy consumption. For example, family setup time is a significant factor for production scheduling in many factories. It might consume more than $20 \%$ of available machine capacity if not handled well, which leads to more energy consumption (Luo et al., 2012; Luo et al., 2015). Thus, this application informs product designers and engineers on energy savings based on product families.

Ecosystem quality management aims to protect the ecosystem and biodiversity. Ecosystem quality is one of the most critical research fields in LCA (Hutchins and Sutherland, 2008). It is difficult to evaluate ecosystem quality and find an effective solution to improve ecosystem quality, as ecosystem are heterogeneous, enormous, and extremely complex to monitor (Goedkoop and Spriensma, 2001). With the adoption of Blockchain technology, all the data on 
input substances and output emissions can be readily shared and integrated to evaluate the environmental performance of a product life cycle. For instance, global climate change poses detrimental effects on ecosystem quality and human health. Activities such as fossil fuel combustion, cement manufacture, coal mining, and biomass burning produce $\mathrm{CO} 2$ emission and $\mathrm{CH} 4$ emission, which results in global climate change (Krishna et al., 2017). Governments can trace and track major emission sources from Blockchain-based LCA system quite rapidly, enabling more proactive measures being implemented to fight climate change.

Waste management is responsible for managing waste (i.e., gas emission, liquid discharge, and solid waste) from its generation to the final disposal. It generally includes collection, transportation, treatment, and disposal of waste. Based on waste emission Blockchains, reliable data sources are utilized to establish a complete picture of the environmental impacts of waste emissions with a product life cycle perspective (Erses Yay, 2015). The analyzed results will help in decision making and strategic planning for managing a wide range of waste types (Khoo, 2019). In addition, product life cycle transparency provides enterprises valuable knowledge to reconsider product use and to redesign products that will generate less or no waste at the end of life of products (Zhang et al., 2019, in press).

Reuse/recycling management plays an important role in waste reduction. Reuse is to use material and components of products again without any reprocessing. Recycling is to convert waste emissions into new materials and components. This application not only controls the wastage of potentially useful substances but also reduces the consumption of virgin raw materials, leading to a better environment and human health. For instance, reusing electronic waste is an important application in reuse management. Electronic waste is one of the most rapidly growing waste streams in the world (Kumar et al., 2017). Components of electronic equipment, including CPUs and hard discs, contain potentially hazardous substances like lead and beryllium, which poses a major threat to public health and ecosystem (Ikhlayel, 2018). However, based on Blockchain data produced in the usage phase, such as running status and lifetime of each component, enterprises can easily identify which component can be reused or need to be discarded. It makes it possible to customize the disposal schemes when consumers want to dispose of their electronic devices. Furthermore, in reuse/recycling management, Blockchains can store material and energy consumption data associated with plastic waste in terms of input resources and output waste emissions (Khoo, 2019).

Product information management is an enabling application for other applications. In order to realize the functionalities of the first four applications, all data related to a product's lifecycle has to be captured and managed properly (Sudarsan et al., 2005). Therefore, this application manages product-related data and information by information modeling architectures, including the Core Product Model (Fenves, 2001), the Open Assembly Model (Rachuri et al., 2003), the Design-Analysis Integration Model (Fenves et al., 2003) and the Product Family 
Evolution Model (Wang et al., 2003). The integration of these models ensures the cohesion and traceability of product data.

Uncertainty treatment management is a decision support application which helps users handle and treat uncertainties when applying LCA. The reliability and credibility of LCA results may be questionable without treating the uncertainties carefully. Thus, uncertainty treatment management plays a significant role in LCA. The treatment of uncertainties is summarized in the following steps: 1) uncertainty identification and characterization; 2) uncertainty analysis; 3) sensitivity analysis; and 4) communication (Igos et al., 2019). In this process, a large number of calculations are needed and they may need the assistance of various LCA software including SimaPro, GaBi and Brightway2. Moreover, judgment methods may be employed to analyze uncertainties by a variety of methods including Analytic Hierarchy Process and Fuzzy Comprehension Evaluation Method.

The users' layer primarily serves governments, NGOs, consumers, and enterprises. Using Blockchain technology, governments can easily monitor the environmental performance of enterprises and industries, which inform governments to make better environmental protection policies and to optimize the structure of industries. NGOs act as third-party users to surveil all the product life cycle stages of the concerned enterprises. They also play an important role in organizing trading markets, for example, carbon emission trading based on smart contract of Blockchain technology. Consumers can make purchasing decisions by taking into consideration the environmental impacts of the products and be informed to use products in an environmentally friendly manner. Enterprises can choose qualified cooperative partners and evaluate whether the environmental impacts of their supply chains and manufacturing processes follow global/national standards.

\subsection{Cost of the System}

The capital cost of Blockchain-based LCA system includes hardware cost and software cost. In this paper, the researchers estimate the capital cost of such a system based on its implementation in a Chinese manufacturer which has four manufacturing shopfloors equipped with 1000 machines and two warehouses with 10 forklifts.

The machines are electrically powered, so smart electricity meters are installed to monitor the consumption of electricity at each machine. The cost of smart electricity meters is $¥ 150,000$ based on an average smart electricity meter price of $¥ 150$ /unit. Each machine is equipped with one RFID reader. The cost of RFID readers is $¥ 3,500,000$ based on an average price of $¥ 3,500$ /unit. Besides, stationary RFID readers are required to deploy at the gates of shopfloors and warehouses at a cost of $¥ 48,000$, assuming there are 12 gates and each of them costs $¥ 4,000$ /unit. There are about 10,000 batches operating daily on the shopfloors. 10,000 tags are attached to the batches and cost $¥ 10,000$ totally, assuming they are priced at $¥ 1$ each. Moreover, each forklift is equipped with a vehicle-mounted computer at a cost of $¥ 5,000$, so the cost of 
vehicle-mounted computers is $¥ 50,000$. The cost of local servers and storage is $¥ 500,000$. Assuming the manufacturer has already deployed 1,000 RFID readers and 10,000 tags to collect manufacturing and logistics data and servers and storage are also in place, the extra cost of $¥ 300,000$ is required to upgrade the storage capacity. Overall, the total cost of hardware used to upgrade the system is $¥ 548,000$. Based on the assumption that the lifetime of the above hardware is five years, the amortized annual cost is $¥ 109,600$.

Software cost is used to develop and maintain the Blockchain-based LCA system. The cost estimate assumes that the manufacturer is fully responsible for the development and maintenance of the Blockchain-based LCA system. Software engineers are employed to complete all the jobs of developing the system. According to a recent survey, the average salary of software engineers in China is $¥ 8,381$ /month. If seven software engineers are employed to develop and maintain the system, the salary of software engineers is $¥ 704,004 /$ year. Apart from salary, the manufacturer incurs other employee-related expenditures including insurance expenses and housing provident fund in China. Generally speaking, these expenditures are about $40 \%$ of the salary cost, which leads to another $¥ 281,602 /$ year. Overall, the cost of software is $¥ 985,606 /$ year. In summary, the capital cost of the system is $¥ 1,095,206 /$ year, the majority of which is spent on software development and maintenance.

Table 1. The capital cost of Blockchain-based LCA system

\begin{tabular}{|c|c|c|c|}
\hline \multicolumn{4}{|l|}{ Hardware } \\
\hline Item & Quantity & Unit Cost & Total Cost \\
\hline Smart electricity meters & 1,000 & $¥ 150$ & $¥ 150,000$ \\
\hline RFID readers for machines (equipped) & 1,000 & $¥ 3,500$ & $¥ 3,500,000$ \\
\hline $\begin{array}{l}\text { Stationary RFID readers for the gates of shopfloors and } \\
\text { warehouses }\end{array}$ & 12 & $¥ 4,000$ & $¥ 48,000$ \\
\hline Tags (equipped) & 10,000 & $¥ 1$ & $¥ 10,000$ \\
\hline Vehicle-mounted computers for forklifts & 10 & $¥ 5,000$ & $¥ 50,000$ \\
\hline Storage capacity & & $¥ 300,000$ & $¥ 300,000$ \\
\hline Total cost of hardware & & & $¥ 548,000$ \\
\hline Total cost of hardware per year (amortized over 5 years) & & & $¥ 109,600$ \\
\hline \multicolumn{4}{|l|}{ Software } \\
\hline Item & $\begin{array}{l}\text { Number of } \\
\text { employees }\end{array}$ & $\begin{array}{r}\text { Monthly } \\
\text { Cost }\end{array}$ & Annual Cost \\
\hline The salary of software engineers & 7 & $¥ 8,381$ & $¥ 704,004$ \\
\hline $\begin{array}{l}\text { Other expenditures for software engineers, such as } \\
\text { insurance expenses and housing provident fund, etc. }\end{array}$ & 7 & $¥ 3,352$ & $¥ 281,602$ \\
\hline Total cost of software & & & $¥ 985,606$ \\
\hline Total capital cost of the system per year & & & $¥ 1,095,206$ \\
\hline
\end{tabular}

\section{Discussion}

\subsection{Potential Technical Issues and Solutions}

Some potential technical issues may hinder the adoption of Blockchain-based LCA system, as many stakeholders are involved in a product's life cycle. The researchers recommend some possible solutions to potential technical issues. 
The first issue is data manipulation challenges. One of the key characteristics in Blockchain technology is data immutability and unforgeability, which means the records cannot be modified or changed without consensus (Kouhizadeh and Sarkis, 2018). However, before records are uploaded and converted into blocks, enterprises may modify and edit data in their own database on purpose and then upload to Blockchains, or upload erroneous records by accident, which leads to the unreliability of data. One approach to solve this issue is to design the system to upload data collected by sensors to the Blockchain network directly, and enterprises can only retrieve data from the Blockchain network. This can prevent an enterprise from modifying or faking data. The other approach is to involve third-party inspection agencies, government agencies, and NGOs in regular data audits to ensure data integrity.

The second issue is that the storage problem will become a challenge when adopting Blockchain technology. With the wide usage of IoT devices, LCA is facing big data. For example, each A380 engine generates 10 TB data every 30 min on a flight journey. More than 12 TB Twitter data are produced daily (Zhong et al., 2015). A large amount of LCA data from IoT devices is to be converted into a large number of blocks for creating Blockchains. Increasing size and number of blocks leads to a storage dilemma when all LCA data are collected and recorded, which is called a bloat problem (Swan, 2015). Hence, the storage scalability problem will confront the stakeholders when they adopt the Blockchain-based LCA system (Panarello et al., 2018). Various techniques are required to tackle the scalability problem, such as advanced storage management as well as cloud computing (Saberi et al., 2019).

The third issue is data transmission challenges after data are collected automatically by smart sensors. There are generally two approaches to transmit the data over the Blockchain network (i.e. real-time data transmission and periodical data transmission). Real-time data transmission ensures that data are shared real-time and users can use the data to make a real-time decision, but it might incur network congestion and finally lead to degradation of data transmission performance. Fortunately, the 5th generation cellular network technology (5G) can improve the efficiency of real-time transmission. However, $5 \mathrm{G}$ is still being rolled out and its full-scale implementation will take time. Therefore, periodical data transmission should be considered in many circumstances. Another consideration is that real-time data transmission is not always necessary, because not all data are utilized to make real-time decisions. Periodical data transmission allows data to be transmitted when the network is idle or less busy, but the time interval between data transmission must be set according to user requirements and data types.

\subsection{Managerial and Policy Implications}

Based on the implementation framework and the system architecture presented above, the researchers advance several general propositions. The first proposition is that integrating IoT in Blockchain-based LCA can drastically improve the efficiency of conducting LCA as IoT 
can collect data automatically in real-time. The second proposition is that integrating big data analytics and visualization can substantially enhance the effectiveness of LCA by increasing the capabilities in data analysis and interpretation. The third proposition is that Blockchainbased LCA can aid a variety of stakeholders to monitor and manage environmental sustainability performance efficiently and effectively, providing trustworthy data and results. The fourth proposition is that there are challenges associated with implementing Blockchainbased LCA in the areas of cost, technical, and incentive issues.

The researchers derive several managerial and policy implications from these general propositions. First, there is a huge benefit in moving to Blockchain-based LCA. This presents a great business opportunity for technology providers. A rush to get into the Blockchain market has been observed in the behaviors of large technology firms as well as those of small and medium-sized enterprises (SMEs) and start-ups. Large technology firms are likely to have an edge in the competition if they have capabilities in smart enabling technologies. This is because the full potential of the Blockchain technology cannot be unlocked without integrating smart enabling technologies such as IoT, big data analytics, cloud computing and data visualization (Aryal et al., 2018a; Saberi et al., 2019). Blockchain start-ups and SMEs need to develop capabilities in smart enabling technologies in order to provide the best solutions to their potential customers.

Second, Blockchain-based LCA can aid businesses to improve the monitoring and management of environmental sustainability performance of their supply chain activities. So far, Blockchain applications in the supply chain have been mainly motived by improving trust, traceability, and transparency. For example, Walmart has had successful proof-of-concept projects in using Blockchain technology to track pork in China and mangos in the United States (Hyperledger, 2018). Given the rising importance of environmental sustainability, businesses should seriously consider implementing Blockchain technology for monitoring environmental impacts. Blockchain-enabled LCA would allow businesses to transparently track important environmental data and show whether commitments were met. Moreover, it makes backtracking on environmental promises or misreporting their progress virtually impossible (futurethinkers.org, 2017). Therefore, the Blockchain-based LCA system proposed in this paper is of practical value.

Third, there are risk and cost associated with implementing Blockchain technology. However, the resulting challenges can be overcome by many businesses. Although the requirement of expertise could be high, the cost of developing a Blockchain-based system is not prohibitive. Businesses, especially large ones which have more resources, should consider making investments in the new technology to continuously improve their sustainability performance and to enhance their reputation. Recent empirical studies (Eccles et al., 2014; Flammer, 2013) found that shareholders reward businesses doing better in sustainability and penalize those that 
neglect their social responsibility. Large businesses also have more power, so they are in a better position to push their supply chain partners and to incentivize them to collaborate in implementing Blockchain technology.

Fourth, Blockchain-based LCA helps firms in achieving operational excellence and improves their competitiveness. It not only reduces the cost of performing LCA operations but also at the same time significantly improves speed and accuracy. Blockchain-enabled data traceability and transparency help firms build superior customer trust and loyalty, which can result in increased sales and better market performance.

Last but not least, governments should consider endorsing or even pushing for the use of Blockchain technology for monitoring environmental impacts. The Blockchain technology did not gain a positive public perception in the beginning due to its origin (i.e., cryptocurrencies). Development of Blockchain-based technological solutions was further hindered by adverse policies about Bitcoin issued by several governments (Mougayar, 2016). However, more recent developments have proved its potential in many areas, for example, supply chain sustainability (Saberi et al., 2019; Wang et al., 2019). Also, Blockchain Technology and smart devices are well recognized for their ability to improve regulatory compliance management (Khaqqi et al., 2018). Given the technical feasibility of Blockchain-based LCA, governments can now formulate policies to encourage or require businesses to use Blockchain-based LCA systems to report their environmental impacts. Recently, the government of the United Arab Emirates (UAE) launched a Blockchain initiative to process 50\% of its government transactions by 2021 (Emem, 2018). To fight climate change, governments across the globe may consider a similar mandate to aggressively promote the use of Blockchain.

\section{Conclusions}

Environmental sustainability has become a pressing issue to society due to the rising concerns on climate change and environmental degradation. LCA is widely used for assessing the environmental impacts of a product or service but collecting reliable data along the supply chain is a major challenge. The emerging Blockchain technology offers an ideal solution to tackle the data reliability issue for conducting LCA due to its distinctive technical attribute of data integrity. Other smart enabling technologies such as IoT, big data analytics, and visualization can be integrated with the Blockchain technology to improve the effectiveness and efficiency of LCA leading towards improved environmental performance of supply chains. Due to the disruptive nature of the Blockchain technology, however, little research has been conducted on the topic to guide practice and future research.

This paper makes several original contributions. First, to the best of our knowledge, this is the very first study that presents the idea of a Blockchain-based LCA system. The research direction is promising and warrants further studies. Second, it presents an implementation 
framework and system architecture of Blockchain-based LCA system which is a significant step towards harmonizing theory and practice of LCA. Third, the innovative Blockchain-based LCA which integrates the use of smart enabling technologies (i.e., IoT, big data analytics, and visualization) offers great potential in improving sustainable supply chain performance through operational excellence. Fourth, the working mechanisms of the system are explained and validated by experienced practitioners. Furthermore, it discusses the potential technical issues in implementing the system and solutions, as well as managerial and policy implications which concern businesses and governments. Overall, this research is a pioneering work in the use of Blockchain technology for advancing the cause of environmental sustainability. It narrows an important knowledge gap in the literature on Blockchain adoption for supply chain sustainability. It is also of practical significance to guide businesses and governments to take actions to improve the environmental performance of their supply chain activities.

This paper has its limitations. The nature of the research work is conceptual. Further works are required to further explore this interesting research domain. Potential application areas include product design, development, and improvement, strategic planning, environmental accounting, public policymaking, marketing, logistics and supply chain design, sustainable supply chain management. Future research may develop a proof-of-concept Blockchain-based LCA system and then have a trial to prove its applicability before a full-scale system development and implementation. Future research may also investigate the barriers of implementing such a Blockchain-based LCA system and devise effective circumventing strategies. Moreover, there are ample research opportunities within the scope of Blockchain and other enabling technologies applications in achieving the vision of a circular economy.

\section{Acknowledgments}

The authors wish to thank three anonymous reviewers and the guest editors for their constructive feedback for improving the manuscript.

\section{References}

Adams, R., Parry, G., Godsiff, P., Ward, P., 2017. The future of money and further applications of the blockchain. Strategic Change 26(5), 417-422.

Al-Saqaf, W., Seidler, N., 2017. Blockchain technology for social impact: opportunities and challenges ahead. Journal of Cyber Policy 2(3), 338-354.

Amendola, S., Lodato, R., Manzari, S., Occhiuzzi, C., Marrocco, G., 2014. RFID Technology for loT-Based Personal Healthcare in Smart Spaces. IEEE Internet of Things Journal 1(2), 144-152.

Aryal, A., Liao, Y., Nattuthurai, P., Li, B., 2018a. The emerging big data analytics and loT in supply chain management: a systematic review. Supply Chain Management: An International Journal. 
Aryal, A., Liao, Y., Nattuthurai, P., Li, B., 2018b. The emerging big data analytics and loT in supply chain management: a systematic review. Supply Chain Management: An International Journal 0(0), null.

Asdrubali, F., Baldinelli, G., D'Alessandro, F., Scrucca, F., 2015. Life cycle assessment of electricity production from renewable energies: Review and results harmonization. Renewable and Sustainable Energy Reviews 42, 1113-1122.

Atzori, L., lera, A., Morabito, G., 2010. The Internet of Things: A survey. Computer Networks 54(15), 2787-2805.

Bahga, A., Madisetti, V.K., 2016. Blockchain platform for industrial internet of things. Journal of Software Engineering and Applications 9(10), 533-546.

Baitz, M., Albrecht, S., Brauner, E., Broadbent, C., Castellan, G., Conrath, P., Fava, J., Finkbeiner, M., Fischer, M., Fullana i Palmer, P., Krinke, S., Leroy, C., Loebel, O., McKeown, P., Mersiowsky, I., Möginger, B., Pfaadt, M., Rebitzer, G., Rother, E., Ruhland, K., Schanssema, A., Tikana, L., 2013. LCA's theory and practice: like ebony and ivory living in perfect harmony? The International Journal of Life Cycle Assessment 18(1), 5-13.

Balaguera, A., Carvajal, G.I., Albertí, J., Fullana-i-Palmer, P., 2018. Life cycle assessment of road construction alternative materials: A literature review. Resources, Conservation and Recycling 132, 37-48.

Bauer, C., Hofer, J., Althaus, H.-J., Del Duce, A., Simons, A., 2015. The environmental performance of current and future passenger vehicles: Life cycle assessment based on a novel scenario analysis framework. Applied Energy 157, 871-883.

Beck, R., Avital, M., Rossi, M., Thatcher, J.B., 2017. Blockchain Technology in Business and Information Systems Research. Business \& Information Systems Engineering 59(6), 381-384.

Buyle, M., Braet, J., Audenaert, A., 2013. Life cycle assessment in the construction sector: A review. Renewable and Sustainable Energy Reviews 26, 379-388.

Cai, H., Xu, L.D., Xu, B., Xie, C., Qin, S., Jiang, L., 2014. IoT-Based Configurable Information Service Platform for Product Lifecycle Management. IEEE Transactions on Industrial Informatics 10(2), 15581567.

Cai, Y., Zhu, D., 2016. Fraud detections for online businesses: a perspective from blockchain technology. Financial Innovation 2(1), 20.

Cerutti, A.K., Beccaro, G.L., Bruun, S., Bosco, S., Donno, D., Notarnicola, B., Bounous, G., 2014. Life cycle assessment application in the fruit sector: State of the art and recommendations for environmental declarations of fruit products. Journal of Cleaner Production 73, 125-135.

Chau, C.K., Leung, T.M., Ng, W.Y., 2015. A review on Life Cycle Assessment, Life Cycle Energy Assessment and Life Cycle Carbon Emissions Assessment on buildings. Applied Energy 143, 395-413. Christensen, T.H., Bhander, G., Lindvall, H., Larsen, A.W., Fruergaard, T., Damgaard, A., Manfredi, S., Boldrin, A., Riber, C., Hauschild, M., 2007. Experience with the use of LCA-modelling (EASEWASTE) in waste management. Waste Management \& Research 25(3), 257-262. 
Christidis, K., Devetsikiotis, M., 2016. Blockchains and Smart Contracts for the Internet of Things. IEEE Access 4, 2292-2303.

Ciroth, A., Fleischer, G., Steinbach, J., 2004. Uncertainty calculation in life cycle assessments. The International Journal of Life Cycle Assessment 9(4), 216.

Conte de Leon, D., Stalick, A.Q., Jillepalli, A.A., Haney, M.A., Sheldon, F.T., 2017. Blockchain: properties and misconceptions. Asia Pacific Journal of Innovation and Entrepreneurship 11(3), 286-300.

Cooper, J.S., Kahn, E., Ebel, R., 2013. Sampling error in US field crop unit process data for life cycle assessment. The International Journal of Life Cycle Assessment 18(1), 185-192.

Corcelli, F., Fiorentino, G., Petit-Boix, A., Rieradevall, J., Gabarrell, X., 2019. Transforming rooftops into productive urban spaces in the Mediterranean. An LCA comparison of agri-urban production and photovoltaic energy generation. Resources, Conservation and Recycling 144, 321-336.

EC (European Commission), 2012. The international reference life cycle data system (ILCD) handbook. https://eplca.jrc.ec.europa.eu/uploads/JRC-Reference-Report-ILCD-Handbook-Towards-moresustainable-production-and-consumption-for-a-resource-efficient-Europe.pdf. (Accessed 22 March 2019).

EC (European Commission), 2013. Commission Recommendation of 9 April 2013 on the use of common methods to measure and communicate the life cycle environmental performance of products and organisations. https://publications.europa.eu/en/publication-detail//publication/93cb8358-b80d-11e2-ab01-01aa75ed71a1/language-en. (Accessed 02 March 2019).

EC (European Commission), 2015. Better regulation toolbox. http://eur-lex.europa.eu/legalcontent/EN/TXT/PDF/?uri=CELEX:52015SC0111\&rid=1. (Accessed 02 March 2019).

Eccles, R.G., Ioannou, I., Serafeim, G., 2014. The Impact of Corporate Sustainability on Organizational Processes and Performance. Management Science 60(11), 2835-2857.

Egilmez, G., Kucukvar, M., Tatari, O., Bhutta, M.K.S., 2014. Supply chain sustainability assessment of the U.S. food manufacturing sectors: A life cycle-based frontier approach. Resources, Conservation and Recycling 82, 8-20.

Emem, M., 2018. UAE Launches Blockchain Initiative to Process 50\% of Govt. Transactions by 2021. https://www.ccn.com/uae-launches-blockchain-initiative-to-process-50-of-govt-transactions-by-

2021. (Accessed 16 May 2019).

Erses Yay, A.S., 2015. Application of life cycle assessment (LCA) for municipal solid waste management: a case study of Sakarya. Journal of Cleaner Production 94, 284-293.

Farooque, M., Zhang, A., 2017. Supply chain management for the circular economy: a review and a classification of terms, Proceedings of the 15th ANZAM Operations, Supply Chain and Services Management Symposium. Queenstown, New Zealand, pp. 9-10.

Farooque, M., Zhang, A., Liu, Y., 2019a. Barriers to circular food supply chains in China. Supply Chain Management: An International Journal 24(5), 677-696.

Farooque, M., Zhang, A., Thürer, M., Qu, T., Huisingh, D., 2019b. Circular supply chain management: A definition and structured literature review. Journal of Cleaner Production 228, 882-900. 
Fenves, S., Choi, Y., Gurumoorthy, B., Mocko, G., Sriram, R., 2003. Master product model for the support of tighter design-analysis integration. National Institute of Standards and Technology, Gaithersburg, MD 20899.

Fenves, S.J., 2001. A core product model for representing design information. US Department of Commerce, Technology Administration, National Institute of ....

Flammer, C., 2013. Corporate Social Responsibility and Shareholder Reaction: The Environmental Awareness of Investors. Academy of Management Journal 56(3), 758-781.

Francisco, K., Swanson, D., 2018. The Supply Chain Has No Clothes: Technology Adoption of Blockchain for Supply Chain Transparency. Logistics 2(1), 2.

Franz, P., Kirchmer, M., 2012. Value-driven business process management: The value-switch for lasting competitive advantage. McGraw Hill Professional.

Fu, B., Shu, Z., Liu, X., 2018. Blockchain Enhanced Emission Trading Framework in Fashion Apparel Manufacturing Industry. Sustainability 10(4), 1105.

futurethinkers.org, 2017. 7 Ways The Blockchain Can Save The Environment and Stop Climate Change. https://futurethinkers.org/blockchain-environment-climate-change/. (Accessed 22 April 2019).

Galletti, A., Papadimitriou, D.-C., 2013. How Big Data Analytics are perceived as a driver for Competitive Advantage : A qualitative study on food retailers. p. 53.

Gbededo, M.A., Liyanage, K., Garza-Reyes, J.A., 2018. Towards a Life Cycle Sustainability Analysis: A systematic review of approaches to sustainable manufacturing. Journal of Cleaner Production 184, 1002-1015.

Genovese, A., Acquaye, A.A., Figueroa, A., Koh, S.C.L., 2017. Sustainable supply chain management and the transition towards a circular economy: Evidence and some applications. Omega 66(Part B), 344-357.

Goedkoop, M., Spriensma, R., 2001. The eco-indicator 99: A damage oriented method for life cycle impact assessment: Methodology report, Second ed. Pré Consultants, B.V. Amersfoort, The Netherlands.

Grewal, D., Motyka, S., Levy, M., 2018. The Evolution and Future of Retailing and Retailing Education. Journal of Marketing Education 40(1), 85-93.

Guinée, J., Heijungs, R., 2017. Introduction to Life Cycle Assessment, in: Bouchery, Y., Corbett, C.J., Fransoo, J.C., Tan, T. (Eds.), Sustainable Supply Chains: A Research-Based Textbook on Operations and Strategy. Springer International Publishing, Cham, pp. 15-41.

Guinée, J.B., Heijungs, R., Huppes, G., Zamagni, A., Masoni, P., Buonamici, R., Ekvall, T., Rydberg, T., 2011. Life Cycle Assessment: Past, Present, and Future. Environmental Science \& Technology 45(1), 90-96.

Guinée, J.B., Heijungs, R., van der Voet, E., 2009. A greenhouse gas indicator for bioenergy: some theoretical issues with practical implications. The International Journal of Life Cycle Assessment 14(4), 328-339. 
Hollberg, A., Ruth, J., 2016. LCA in architectural design-a parametric approach. The International Journal of Life Cycle Assessment 21(7), 943-960.

Hospido, A., Davis, J., Berlin, J., Sonesson, U., 2010. A review of methodological issues affecting LCA of novel food products. The International Journal of Life Cycle Assessment 15(1), 44-52.

Hutchins, M.J., Sutherland, J.W., 2008. An exploration of measures of social sustainability and their application to supply chain decisions. Journal of Cleaner Production 16(15), 1688-1698.

Hyperledger, 2018. How Walmart brought unprecedented transparency to the food supply chain with Hyperledger Fabric. https://www.hyperledger.org/wpcontent/uploads/2019/02/Hyperledger CaseStudy Walmart Printable V4.pdf. (Accessed 16 May 2019).

lansiti, M., Lakhani, K.R., 2017. The truth about blockchain. Harvard Business Review 95(1), 118-127. Igos, E., Benetto, E., Meyer, R., Baustert, P., Othoniel, B., 2019. How to treat uncertainties in life cycle assessment studies? The International Journal of Life Cycle Assessment 24(4), 794-807.

Ikhlayel, M., 2018. An integrated approach to establish e-waste management systems for developing countries. Journal of Cleaner Production 170, 119-130.

Jakhar, S.K., Rathore, H., Mangla, S.K., 2018. Is lean synergistic with sustainable supply chain? An empirical investigation from emerging economy. Resources, Conservation and Recycling 139, 262-269. Jensen, A.A., 1998. Life cycle assessment (LCA): a guide to approaches, experiences and information sources. European Communities.

Jolliet, O., Dubreuil, A., Gloria, T., Hauschild, M., 2005. Progresses in Life Cycle Impact Assessment within the UNEP/SETAC Life Cycle Initiative. The International Journal of Life Cycle Assessment 10(6), 447-448.

Khaqqi, K.N., Sikorski, J.J., Hadinoto, K., Kraft, M., 2018. Incorporating seller/buyer reputation-based system in blockchain-enabled emission trading application. Applied Energy 209, 8-19.

Khoo, H.H., 2019. LCA of plastic waste recovery into recycled materials, energy and fuels in Singapore. Resources, Conservation and Recycling 145, 67-77.

Kouhizadeh, M., Sarkis, J., 2018. Blockchain Practices, Potentials, and Perspectives in Greening Supply Chains. Sustainability 10(10), 3652.

Krishna, I.M., Manickam, V., Shah, A., Davergave, N., 2017. Chapter Five - Life Cycle Assessment, Environmental management: science and engineering for industry. Butterworth-Heinemann, pp. 5775.

Kumar, A., Holuszko, M., Espinosa, D.C.R., 2017. E-waste: An overview on generation, collection, legislation and recycling practices. Resources, Conservation and Recycling 122, 32-42.

Lake, A., Acquaye, A., Genovese, A., Kumar, N., Koh, S.C.L., 2015. An application of hybrid life cycle assessment as a decision support framework for green supply chains. International Journal of Production Research 53(21), 6495-6521.

Levasseur, A., Cavalett, O., Fuglestvedt, J.S., Gasser, T., Johansson, D.J.A., Jørgensen, S.V., Raugei, M., Reisinger, A., Schivley, G., Strømman, A., Tanaka, K., Cherubini, F., 2016. Enhancing life cycle impact 
assessment from climate science: Review of recent findings and recommendations for application to LCA. Ecological Indicators 71, 163-174.

Li, Z., Barenji, A.V., Huang, G.Q., 2018a. Toward a blockchain cloud manufacturing system as a peer to peer distributed network platform. Robotics and Computer-Integrated Manufacturing 54, 133-144.

Li, Z., Guo, H., Wang, W.M., Guan, Y., Barenji, A.V., Huang, G.Q., McFall, K.S., Chen, X., 2019. A Blockchain and AutoML Approach for Open and Automated Customer Service. IEEE Transactions on Industrial Informatics, 1-1.

Li, Z., Wang, W.M., Liu, G., Liu, L., He, J., Huang, G.Q., 2018b. Toward open manufacturing: A crossenterprises knowledge and services exchange framework based on blockchain and edge computing. Industrial Management \& Data Systems 118(1), 303-320.

Luo, H., Huang, G.Q., Shi, Y., Qu, T., Zhang, Y.F., 2012. Hybrid flowshop scheduling with family setup time and inconsistent family formation. International Journal of Production Research 50(6), 14571475.

Luo, H., Zhang, A., Huang, G.Q., 2015. Active scheduling for hybrid flowshop with family setup time and inconsistent family formation. Journal of Intelligent Manufacturing 26(1), 169-187.

Luthra, S., Mangla, S.K., 2018. When strategies matter: Adoption of sustainable supply chain management practices in an emerging economy's context. Resources, Conservation and Recycling 138, 194-206.

Mangla, S.K., Kusi-Sarpong, S., Luthra, S., Bai, C., Jakhar, S.K., Khan, S.A., 2019. Operational excellence for improving Sustainable Supply Chain Performance. Resources, Conservation and Recycling 142, 277-278.

Mangla, S.K., Luthra, S., Mishra, N., Singh, A., Rana, N.P., Dora, M., Dwivedi, Y., 2018. Barriers to effective circular supply chain management in a developing country context. Production Planning \& Control 29(6), 551-569.

Marsal-Llacuna, M.-L., 2018. Future living framework: Is blockchain the next enabling network? Technological Forecasting and Social Change 128, 226-234.

Matos, S., Hall, J., 2007. Integrating sustainable development in the supply chain: The case of life cycle assessment in oil and gas and agricultural biotechnology. Journal of Operations Management 25(6), 1083-1102.

Mougayar, W., 2016. The business blockchain: promise, practice, and application of the next Internet technology. John Wiley \& Sons.

Muralikrishna, I.V., Manickam, V., 2017. Life cycle assessment, Environmental Management: Science and Engineering for Industry. Butterworth-Heinemann, UK, pp. 57-75.

Nakamoto, S., 2008. Bitcoin: A peer-to-peer electronic cash system.

Nasir, M.H.A., Genovese, A., Acquaye, A.A., Koh, S.C.L., Yamoah, F., 2017. Comparing linear and circular supply chains: A case study from the construction industry. International Journal of Production Economics 183(Part B), 443-457. 
Niero, M., Negrelli, A.J., Hoffmeyer, S.B., Olsen, S.I., Birkved, M., 2016. Closing the loop for aluminum cans: Life Cycle Assessment of progression in Cradle-to-Cradle certification levels. Journal of Cleaner Production 126, 352-362.

Niero, M., Olsen, S.I., 2016. Circular economy: To be or not to be in a closed product loop? A Life Cycle Assessment of aluminium cans with inclusion of alloying elements. Resources, Conservation and Recycling 114(Supplement C), 18-31.

Norgate, T.E., Jahanshahi, S., Rankin, W.J., 2007. Assessing the environmental impact of metal production processes. Journal of Cleaner Production 15(8), 838-848.

Notarnicola, B., Sala, S., Anton, A., McLaren, S.J., Saouter, E., Sonesson, U., 2017. The role of life cycle assessment in supporting sustainable agri-food systems: A review of the challenges. Journal of Cleaner Production 140, 399-409.

Panarello, A., Tapas, N., Merlino, G., Longo, F., Puliafito, A., 2018. Blockchain and loT Integration: A Systematic Survey. Sensors 18(8), 2575.

Pérez-López, P., González-García, S., Ulloa, R.G., Sineiro, J., Feijoo, G., Moreira, M.T., 2014. Life cycle assessment of the production of bioactive compounds from Tetraselmis suecica at pilot scale. Journal of Cleaner Production 64, 323-331.

Puthal, D., Malik, N., Mohanty, S.P., Kougianos, E., Yang, C., 2018. The Blockchain as a Decentralized Security Framework [Future Directions]. IEEE Consumer Electronics Magazine 7(2), 18-21.

Queiroz, M.M., Telles, R., Bonilla, S.H., 2019. Blockchain and supply chain management integration: a systematic review of the literature. Supply Chain Management: An International Journal 0(0), null.

Rebitzer, G., Ekvall, T., Frischknecht, R., Hunkeler, D., Norris, G., Rydberg, T., Schmidt, W.P., Suh, S., Weidema, B.P., Pennington, D.W., 2004. Life cycle assessment: Part 1: Framework, goal and scope definition, inventory analysis, and applications. Environment International 30(5), 701-720.

Roy, P., Nei, D., Orikasa, T., Xu, Q., Okadome, H., Nakamura, N., Shiina, T., 2009. A review of life cycle assessment (LCA) on some food products. Journal of Food Engineering 90(1), 1-10.

Saberi, S., Kouhizadeh, M., Sarkis, J., Shen, L., 2019. Blockchain technology and its relationships to sustainable supply chain management. International Journal of Production Research 57(7), 21172135.

Schroeder, P., Dewick, P., Kusi-Sarpong, S., Hofstetter, J.S., 2018. Circular economy and power relations in global value chains: Tensions and trade-offs for lower income countries. Resources, Conservation and Recycling 136, 77-78.

Scientific Applications International Corporation, 2006. Life-cycle assessment: principles and practice. National Risk Management Research Laboratory Office Of Research And Development U.S. Environmental Protection Agency, Cincinnati, Ohio.

Scott, B., Loonam, J., Kumar, V., 2017. Exploring the rise of blockchain technology: Towards distributed collaborative organizations. Strategic Change 26(5), 423-428.

Sikorski, J.J., Haughton, J., Kraft, M., 2017. Blockchain technology in the chemical industry: Machineto-machine electricity market. Applied Energy 195, 234-246. 
Song, M.-L., Fisher, R., Wang, J.-L., Cui, L.-B., 2018. Environmental performance evaluation with big data: theories and methods. Annals of Operations Research 270(1), 459-472.

Sudarsan, R., Fenves, S.J., Sriram, R.D., Wang, F., 2005. A product information modeling framework for product lifecycle management. Computer-Aided Design 37(13), 1399-1411.

Swan, M., 2015. Blockchain: Blueprint for a new economy. " O'Reilly Media, Inc.".

Tama, B.A., Kweka, B.J., Park, Y., Rhee, K., 2017. A critical review of blockchain and its current applications, 2017 International Conference on Electrical Engineering and Computer Science (ICECOS). pp. 109-113.

Tao, F., Zuo, Y., Xu, L.D., Lv, L., Zhang, L., 2014a. Internet of Things and BOM-Based Life Cycle Assessment of Energy-Saving and Emission-Reduction of Products. IEEE Transactions on Industrial Informatics 10(2), 1252-1261.

Tao, F., Zuo, Y., Xu, L.D., Zhang, L., 2014b. IoT-Based Intelligent Perception and Access of Manufacturing Resource Toward Cloud Manufacturing. IEEE Transactions on Industrial Informatics 10(2), 1547-1557.

Tapscott, D., Tapscott, A., 2017. How blockchain will change organizations. MIT Sloan Management Review 58(2), 10.

Tian, F., 2016. An agri-food supply chain traceability system for China based on RFID \&amp; blockchain technology, 2016 13th International Conference on Service Systems and Service Management (ICSSSM). pp. 1-6.

Treiblmaier, H., 2018. The impact of the blockchain on the supply chain: a theory-based research framework and a call for action. Supply Chain Management: An International Journal 23(6), 545-559. UNEP (United Nations Environment Programme), 2012. Global Chemicals Outlook: synthesis report for decision-makers. https://www.unenvironment.org/resources/report/global-chemicals-outlooksynthesis-report-decision-makers. (Accessed 24 March 2019).

Viriyasitavat, W., Da Xu, L., Bi, Z., Sapsomboon, A., 2018. Blockchain-based business process management (BPM) framework for service composition in industry 4.0. Journal of Intelligent Manufacturing.

von Bahr, B., Steen, B., 2004. Reducing epistemological uncertainty in life cycle inventory. Journal of Cleaner Production 12(4), 369-388.

von Gleich, A., Steinfeldt, M., Petschow, U., 2008. A suggested three-tiered approach to assessing the implications of nanotechnology and influencing its development. Journal of Cleaner Production 16(8), 899-909.

Wang, F., Fenves, S.J., Sudarsan, R., Sriram, R.D., 2003. Towards modeling the evolution of product families, Proceedings of the 2003 ASME Design Engineering Technical Conferences.

Wang, Y., Han, J.H., Beynon-Davies, P., 2019. Understanding blockchain technology for future supply chains: a systematic literature review and research agenda. Supply Chain Management: An International Journal 24(1), 62-84. 
Weidema, B., Wenzel, H., Petersen, C., Hansen, K., 2004. The product, functional unit and reference flows in LCA. Environmental News 70, 1-46.

White, G.R.T., 2017. Future applications of blockchain in business and management: A Delphi study. Strategic Change 26(5), 439-451.

Yuan, Y., Wang, F., 2018. Blockchain and Cryptocurrencies: Model, Techniques, and Applications. IEEE Transactions on Systems, Man, and Cybernetics: Systems 48(9), 1421-1428.

Yue, X., Wang, H., Jin, D., Li, M., Jiang, W., 2016. Healthcare Data Gateways: Found Healthcare Intelligence on Blockchain with Novel Privacy Risk Control. Journal of Medical Systems 40(10), 218.

Zhang, A., Luo, H., Huang, G.Q., 2013. A bi-objective model for supply chain design of dispersed manufacturing in China. International Journal of Production Economics 146 (1), 48-58.

Zhang, A., Luo, W., Shi, Y., Chia, S., Sim, Z., 2016. Lean and Six Sigma in logistics: a pilot survey study in Singapore. International Journal of Operations \& Production Management 36(11), 1625-1643.

Zhang, A., Venkatesh, V.G., Liu, Y., Wan, M., Qu, T., Huisingh, D., 2019, in press. Barriers to Smart Waste Management for a Circular Economy in China. Journal of Cleaner Production.

Zhong, R.Y., Huang, G.Q., Dai, Q.Y., Zhang, T., 2014. Mining SOTs and dispatching rules from RFIDenabled real-time shopfloor production data. Journal of Intelligent Manufacturing 25(4), 825-843.

Zhong, R.Y., Huang, G.Q., Lan, S., Dai, Q.Y., Chen, X., Zhang, T., 2015. A big data approach for logistics trajectory discovery from RFID-enabled production data. International Journal of Production Economics 165, 260-272.

Zuo, Y., Tao, F., Nee, A.Y.C., 2018. An Internet of things and cloud-based approach for energy consumption evaluation and analysis for a product. International Journal of Computer Integrated Manufacturing 31(4-5), 337-348. 